\title{
Work holding assessment of an UV adhesive and fixture design method
}

\author{
Shaoming Yao ${ }^{1}$ (D) Erdem Ozturk ${ }^{1} \cdot$ David Curtis $^{1} \cdot$ Tom McLeay $^{1}$
}

Received: 15 March 2019 / Accepted: 4 November 2019 / Published online: 27 November 2019

(C) The Author(s) 2019

\begin{abstract}
Adhesive work holding can be used to minimize clamping distortion and provide greater access to a work piece during machining. This paper proposes shear and tensile strength criteria to evaluate the work holding strength of adhesive grippers and definition of a strength safety coefficient of adhesive grippers. It also demonstrates a case study of work holding design with an UV adhesive for a grinding process based on a strength criteria explained in the paper. A test rig has been designed and manufactured to assess the capability of an adhesive work holding material. Tests include measurement of strength and repeatability of adhesion under different film thicknesses, curing times and pre-cleaning methods. The test shows the strength repeatability is less than $\pm 20 \%$, which is good enough for many work holding applications. A shear-tensile combined strength can be evaluated by the strength sphere in a fixture design of a specific part geometry for production by the combined safety coefficient. Following the test rig assessment, a fixture has been designed with 3 grippers to demonstrate the adhesive for a grinding process with a simple part geometry. The method has a high potential for application in industry, and is not limited to the given part geometry and machining method. The grinding test shows that the adhesive work holding is strong enough for the application and that similar results can be expected for milling and turning with a good gripper arrangement.
\end{abstract}

Keywords Work holding $\cdot$ UV adhesive $\cdot$ Fixture design $\cdot$ Machining $\cdot$ Grinding

\section{Introduction}

In near net machining, materials supplied to a machining process tend to be flexible and intricate in geometry due to thin walls or hollow sections. In many cases, flexible parts are subject to part deflection due to clamping before machining starts. The clamping force and work holding design are influential factors on the magnitude of the part deflection.

Shaoming Yao

s.yao@sheffield.ac.uk

Erdem Ozturk

e.ozturk@sheffield.ac.uk

David Curtis

d.curtis@sheffield.ac.uk

Tom McLeay

T.McLeay@sheffield.ac.uk

1 AMRC with Boeing, The University of Sheffield, Advanced Manufacturing Park, Wallis Way, Catcliffe, Rotherham S60 5TZ, UK
Encapsulant work holding techniques are popular in industry. These consist of moulding a material around a work piece so as to encapsulate and stiffen the system, but leaving access for the regions that require machining work. The method is suitable for complicated geometries or materials supplied with large geometry variation, such as blades or vanes. The main disadvantage is the time and cost of carrying out encapsulant moulding before machining, then removal, cleaning and disposal of the encapsulant material after machining. An encapsulant is a phase change (solid-liquid-solid) material, and can be a low melting temperature alloy (such as Cerro), wax, polymer (such as Rigidax) [1] and even magneto rheologic fluid [2,3]. Sanjay and Paul [4] presented a fixturing concept of free part encapsulation for 'complex shaped components' (components with complicated geometries).

Common temperature-induced phase change materials are thermoplastic materials including low-temperature alloy and wax. Rong et al. [2] presented a method which uses a magnetic field to control the phase change of a magnetorheological fluid and therefore holds the part in place.

In some cases, only one surface on the part is available for clamping, such as one side of the part for clamping and the 
other 5 sides left to machine in one go. In this scenario, a vacuum is a good solution to hold the part on one side. It is extensively used for large flexible parts, such as aerofoils, but is also used for part handling $[5,6]$. Vacuum solutions require fixture surface to match the part surface closely. Without this, a vacuum cannot be generated within the cavity between the fixture and the part. This is difficult to achieve if the material supply has large geometry variation. A further disadvantage is that the holding force of a vacuum solution is low per unit area, when compared with typical cutting forces. Magnetic work holding [7-9] is also a good option as employed in a magnetic chuck [7], but this method is applicable for ferric materials only. In aerospace industry, most of the parts are made of aluminium, titanium and nickel alloys and composites that are non-ferrous.

Adhesive work holding can be a good choice if the abovelisted methods are not suitable for a given process. Adhesive work holding will not introduce clamping distortion and will hold the part as it is. Adhesives must be cured to operate, and can be classified as physical curing and chemical curing types. Curing type adhesives can further be classified as onecomponent and two-component formulas. Most of the physical curing adhesives are one component. Chemical adhesives may be one or two components [10]. Chemical curing adhesive tends to take longer for a chemical reaction to take place, whereas physical curing adhesives tend to be 'instant'. The most popular physical curing adhesives are thermal adhesive and ultraviolet (UV) adhesive. Few publications reported thermal adhesive used in work holding up to now. Ultraviolet (UV) adhesive can be used to fixture thin wall castings for grinding which is prone to flexing when conventional mechanical clamp is used. UV curing is the process by which ultraviolet light is used to initiate a photochemical reaction that generates a cross-linked network of polymers. UV curing is adaptable to printing, coating, decorating, stereolithography and in the assembly of a variety of products and materials. In comparison with other technologies, curing with UV energy may be considered a low-temperature and a high-speed process. It is also a solventless process as cure occurs via direct polymerization.

A patent has been filed for use of adhesive grippers to fixture a part to be machined [11]. This technology uses adhesive to temporarily bond a work piece to numerous cylindrical grippers installed in a fixture plate. Once the adhesive is cured via ultraviolet (UV) light, the work piece is securely held at a known datum location in an undistorted, free-state condition. After machining, the adhesive bonds between the grippers and work piece are easily broken and any excess adhesive is removed from the completed part via a quick, steam-cleaning wash. Shen et.al. developed an adhesive-based reconfigurable pallet to fixture a part family with the same pallet [12] rather than a specific fixture for every member.
Doll and de Meter investigated the adhesive shrinking during photopolymerization in a photo-activated adhesive workholding (PAAW) fixture [13]. The shrinkage led to the build-up of residual stresses that may distort the work piece and/or reduce the external load capacity of the adhesive joints.

De Meter investigated and characterized the strength, ductility and failure modes of a light-activated adhesive gripper (LAAG) subject to axial loading and shear loading [14] and determined the yield strength with regard to tensile and shear. De Meter and Kumar further investigated a hard-to-hold part, namely a casting bracket, with a tight tolerance $[15,16]$. Multiple UV grippers were applied along the bracket and the cycle time and cost were analyzed. However, they did not create a method or general rules for fixture design with LAAG, such as how many grippers is enough, what arrangement should be used and what gripper size is enough or better. They did quantify yield strength and demonstrated a specific work holding application.

Raffles et al. [17] assessed a UV adhesive for work holding. They designed the experiments with two pins joined together by the UV adhesive and the butting joint bonding strength was assessed using a universal test machine with consideration of different (1) curing time, (2) bonding angle, (3) curvature, (4) non-conformal surface (two surface with different radii), (5) surface roughness and (6) degrease. However, the authors did not evaluate the tensile strength and shear strength of the adhesive joint and did not investigate the film thickness impact on the strength. Furthermore, the authors did not report the measured tensile and shear strength of the adhesive, which makes it hard to use the results for fixture design.

The Blue Photon system [18] is a commercial product available on the market, which is composed of grippers, UV adhesive, curing device and UV light source. This paper tests the ability and repeatability of a specific UV adhesive with the Blue Photon system. It presents a strength criterion, design and demonstration of a fixture with specific grippers for a grinding trial.

\section{Load capacity of UV adhesive gripper}

An adhesive joint tends to be a thin film over the contact area. The strength can be defined in tension and shear.

A Blue Photon Gripper 12130 [18] is shown in Fig. 1. The gripper is made of carbon steel and the ground top surface 1 has a diameter of $11.68 \mathrm{~mm}\left(0.46^{\prime \prime}\right)$, which is for applying adhesive. The green area 2 is glass for UV transmission, which goes through the gripper. The stage 3 is for axial positioning, the thread 4 is for fastening and hexangular cap 5 is for operations, such as fastening and removal. The adhesive used is called BlueGrip S2 [18]. The recommended temperature range is $0-70{ }^{\circ} \mathrm{C}$ and further temperature increase can reduce the strength of both tensile and shear until $150{ }^{\circ} \mathrm{C}$ the 


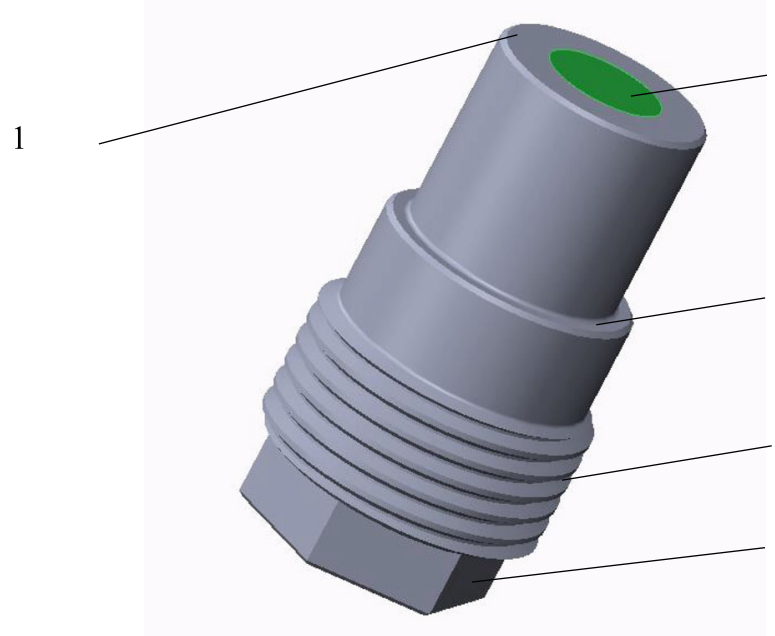

Fig. 1 Test gripper, 1. Top surface, 2. Glass for UV pass, 3. Stage, 4. Thread, 5. Hexangular cap

strength loss is up to $80-90 \%$. The joint can be broken by rotating the gripper head to disassemble the fixture-part setup in room temperature.

The adhesive takes a form of paste. To apply adhesive work holding on a part, first fix the gripper or grippers in a fixture and drop the adhesive on the top of the gripper. After that, position the part on the top of the gripper or grippers with a gap. In the end, apply UV light through the glass of the gripper, as shown in Fig. 1, and the adhesive can be cured with a given curing time. The gripper can be in any orientation and the adhesive is sticky and would not drop due to the effect of gravity but benefits from a level of positive location and nesting to maintain gap thickness during curing.

The size of the adhesive joint does not affect its strength of unit area. Force/area ratio would be constant even if more samples were used, which is equivalent to the film strength. If high forces are required, two options are available: either put in more grippers or choose a bigger gripper to increase the area.

\subsection{Tensile load capacity and test}

The tensile load capacity is the maximum normal force on the top surface of the gripper, which is proportional with the area of the top surface.

$F_{\mathrm{t} 0}=\sigma_{\mathrm{t} 0} A$

where $F_{\mathrm{t} 0}$ is the tensile load capacity of the gripper, $\sigma_{\mathrm{t} 0}$ is the film tensile strength and $A$ is the top surface area, $A=1.07 \times$ $10^{-4} \mathrm{~m}^{2}$. The test rig is as shown in Fig. 2. The load cell used is S-Beam Load Cell, from Force Logic UK Ltd. [19]. The maximum load is $1000 \mathrm{~kg}$, maximum error is $0.05 \%$ and repeatability is $0.02 \%$.
The test rig setup is shown as in Fig. 2. A torque on the load bolt is applied and it is slowly increased until the joint is broken and the maximum force acquired on the load cell is used to calculate the tensile strength.

The film thickness was varied from 0.5 to $3.0 \mathrm{~mm}$ with step of $0.5 \mathrm{~mm}$ and tests were repeated 5 times to check repeatability. Sometimes, the breakage happens on the gripper top and leaves the adhesive residual on the surface of the test piece, as shown in Fig. 3 a; sometimes, breakage happens on the surface of the test piece, as shown in Fig. 3 b, and sometime on both test piece and gripper, as shown in Fig. $3 \mathrm{c}$.

The tensile load capacity results are listed in Table 1.

Adhesive film tensile strengths, $\sigma_{\mathrm{t} 0}$, are listed in Table 2 and plotted in Fig. 4. The maximum repeatability is $\pm 19.9 \%$ which was the case with the $2-\mathrm{mm}$ film thickness tests. The strength increases steadily from thickness of 0.5 to $2.0 \mathrm{~mm}$ and if the thickness is increased further, the strength quickly reduced as shown in Fig. 4, which is possibly because the curing time is not enough for thicker films.

\subsection{Shear load capacity and test}

The shear load capacity is the maximum shear force on the top surface of the gripper, which is proportional with the area of the top surface.

$F_{\mathrm{s} 0}=\sigma_{\mathrm{s} 0} A$

where $F_{\mathrm{s} 0}$ is the shear force on the gripper, $\sigma_{\mathrm{s} 0}$ is the film shear strength and $A$ is the top surface area. The test rig for shear testing is presented in Fig. 5. The same load cell that was used in the tensile tests was used in this setup. The load The film thickness was varied from 0.5 to $3.0 \mathrm{~mm}$ with step of $0.5 \mathrm{~mm}$ and tests repeated 5 times to check repeatability.

The load, $F_{\mathrm{s} 0}$, and load reaction of the load cell are selfbalanced and the force applied on the gripper top is as shown in Fig. 6. The test piece slides on the gripper top over the two slide supports on both side of the gripper. The test piece thickness is negligible comparing with the slide support distance and the test piece thickness introduced error can be neglected.

In the shear tests, the breakage happens on the gripper top surface and leaves the adhesive residual on the test piece nearly all the time, as shown in Fig. 7.

Shear load capacity of the adhesive is presented in Table 3 . Adhesive shear strengths, $\sigma_{\mathrm{s} 0}$, are listed in Table 4 and plotted in Fig. 8. The maximum repeatability is $\pm 16.5 \%$ which happened with the 3-mm film thickness tests. The shear strength decreases slightly when film thickness increases from 0.5 to $1.5 \mathrm{~mm}$ and then remains relatively stable. If further increase occurs, after $2.5 \mathrm{~mm}$, the shear strength decreases again, which is probably because the curing time is not enough for the thickest film thickness of $3 \mathrm{~mm}$. 
Fig. 2 Tensile test rig

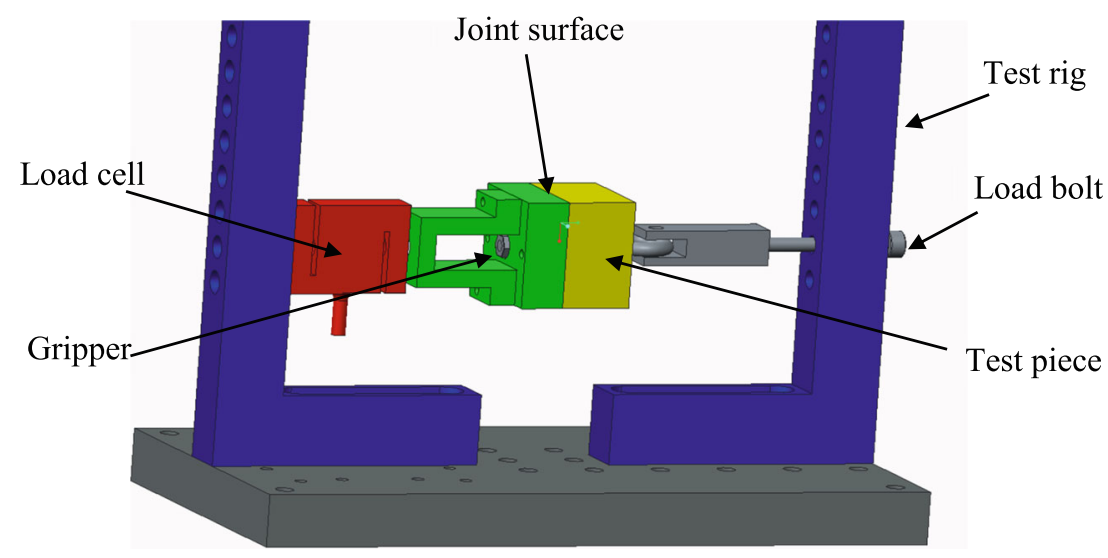

\subsection{Curing time effect}

\subsubsection{Curing time effects on tensile strength}

Curing time is one of the elements that affect the strength of adhesive. Curing time is varied from 20 to $100 \mathrm{~s}$ with steps of $20 \mathrm{~s}$ to investigate curing time effect on tensile strength with film thicknesses of 0.5 and $3.0 \mathrm{~mm}$. The test results are plotted in Fig. 9. For the thin film, $0.5 \mathrm{~mm}$, the tensile strength increases with curing time and tends to saturate around $60 \mathrm{~s}$; beyond this, the tensile strength decreases which may be due to the measurement setup and operation. For the thicker film, namely $3.0 \mathrm{~mm}$, the tensile strength increases quickly at the beginning and then keeps constant increase with the curing time, that means a thick film needs a longer curing time to achieve a higher strength.

\subsubsection{Curing time effect on shear strength}

Curing time was varied from 20 to $100 \mathrm{~s}$ with step of $20 \mathrm{~s}$ to investigate curing time effects on shear strength with film thickness of 0.5 and $3.0 \mathrm{~mm}$. The test results are plotted in Fig. 10. For the thin film, $0.5 \mathrm{~mm}$, the shear strength increases with curing time and saturates around $60 \mathrm{~s}$ and after $60 \mathrm{~s}$ the shear strength does not increase; for the thick film, $3.0 \mathrm{~mm}$, the tensile strength increases constantly with the curing time, that means a thick film needs a long curing time to achieve a good strength.

\subsection{Surface cleaning and degreasing effects}

\subsubsection{Cleaning and degreasing effects on tensile strength}

Surface cleaning and degreasing affects the joint strength considerably. The most common contaminant in a machining workshop is coolant. To test cleaning and degreasing method effects, the test piece surface was dipped in a coolant with concentration of $10 \%$ MicroSol® 585XT [20], for $60 \mathrm{~s}$ and the contaminated surface was used to conduct the test.

By considering the available and common cleaning and degreasing tools and methods in a machining workshop, four methods were proposed for testing:

1. Use pressured air to blow to dry test surface and no degreasing

2. Clean test surface with a tissue and no degreasing
Fig. 3 Tensile breakage (a) on the gripper top (b) on the surface of the test piece and (c) both gripper and test piece

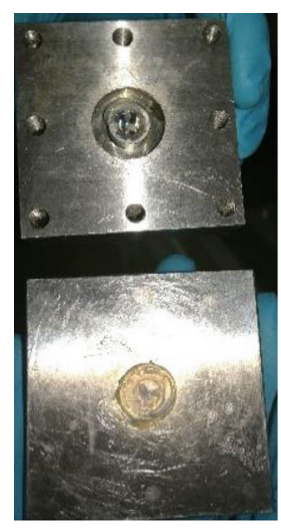

(a)

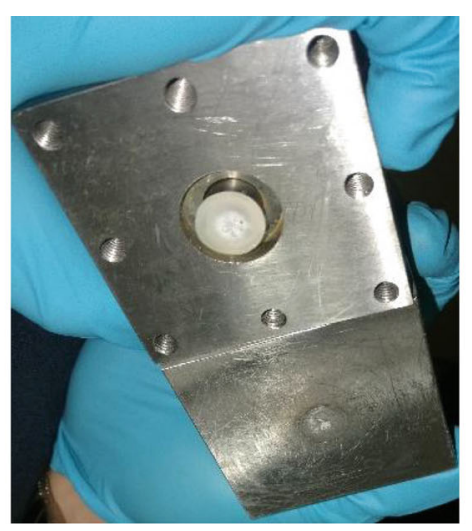

(b)

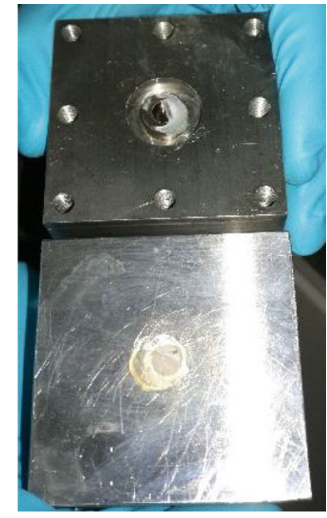

(c) 
Table 1 Adhesive tensile load capacity test, $F_{\mathrm{t} 0}(N)$, curing time $60 \mathrm{~s}$ and $A=1.07 \times 10^{-4} \mathrm{~m}^{2}$

\begin{tabular}{lllllll}
\hline \multicolumn{7}{c}{ Thickness, mm } \\
\cline { 2 - 6 } Test & 0.5 & 1.0 & 1.5 & 2.0 & 2.5 & 3.0 \\
\hline 1 & 1780 & 1382 & 1940 & 2130 & 1250 & 1320 \\
2 & 1835 & 1880 & 1646 & 2070 & 1362 & 1230 \\
3 & 1618 & 1500 & 1706 & 1820 & 1570 & 1100 \\
4 & 1710 & 1526 & 1920 & 1700 & 1330 & 1620 \\
5 & 1670 & 1990 & 1635 & 1990 & 1610 & 1450 \\
Average & 1723 & 1724 & 1769 & 1942 & 1424 & 1344 \\
\hline
\end{tabular}

3. Use pressured air to blow to dry test surface, degrease the surface and use pressure air to dry test surface again

4. Degrease the surface first and use tissue to make it dry.

Effect of cleaning method on the tensile strength was plotted in Fig. 11 for a representative case where film thickness was $1.0 \mathrm{~mm}$ and curing time was $60 \mathrm{~s}$. The results show that without degreasing, method 1 , the strength is rather low, only 3.48 MPa. Tissue cleaning, method 2, resulted in a good result, 18.15 MPa. However, this is probably applicable when the test surface has a good surface finish due to a bad surface finish may make the coolant remain. In this case, the test surface was a ground surface.

Method 3 resulted in a good tensile strength as well, which was $17.83 \mathrm{MPa}$. This method is expected to perform better with test surfaces with poor surface finish due to the fact that pressurized air can blow away the coolant in micro surface features. The result of method 4 coincided with the average value of Table 2, which was $15.77 \mathrm{MPa}$, for film thickness of $1.0 \mathrm{~mm}$. Considering the variability of test results though, it can be concluded that all methods except the first method achieved similar tensile strength.

Table 2 Adhesive tensile strength, $\sigma_{\mathrm{t} 0}(\mathrm{MPa})$, with curing time of $60 \mathrm{~s}$

\begin{tabular}{lllllll}
\hline \multicolumn{7}{c}{ Thickness, mm } \\
\cline { 2 - 7 } Test & 0.5 & 1.0 & 1.5 & 2.0 & 2.5 & 3.0 \\
\hline 1 & 16.32 & 12.67 & 17.79 & 19.53 & 11.46 & 12.10 \\
2 & 16.82 & 17.24 & 15.09 & 18.98 & 12.49 & 11.28 \\
3 & 14.83 & 13.75 & 15.64 & 16.69 & 14.39 & 10.09 \\
4 & 15.68 & 13.99 & 17.60 & 15.59 & 12.19 & 14.85 \\
5 & 15.31 & 18.24 & 14.99 & 18.24 & 14.76 & 13.29 \\
Average & 15.79 & 15.81 & 16.22 & 17.80 & 13.06 & 12.32 \\
Variation, $\pm \%$ & 6.1 & 19.9 & 7.6 & 12.4 & 12.3 & 18.1 \\
\hline
\end{tabular}

The variation is the maximum deviation from the average divided by the average

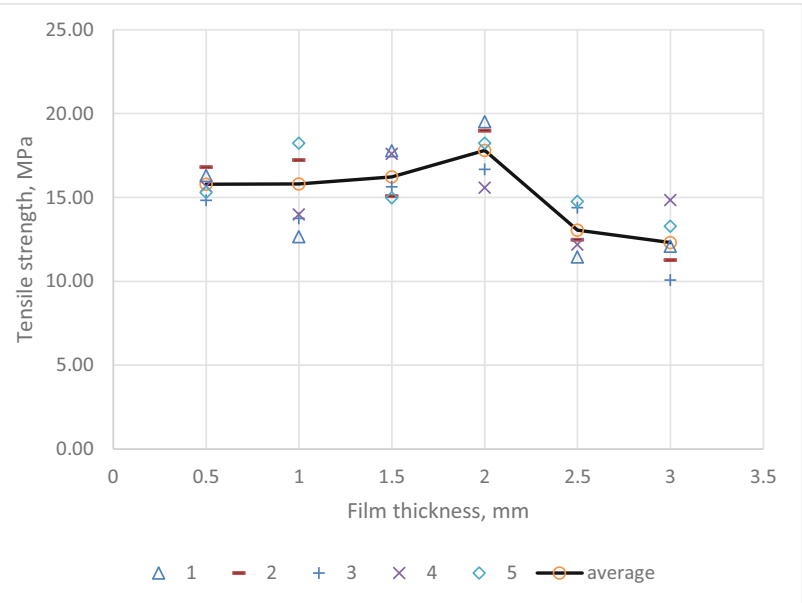

Fig. 4 Film tensile strength

\subsubsection{Cleaning and degreasing effects on shear strength}

Four same cleaning methods are compared as in tensile test to test the cleaning and degreasing method effects on shear strength.

The test results are plotted in Fig. 12 with film thickness of $1.0 \mathrm{~mm}$ and curing time of $60 \mathrm{~s}$. The results show without degreasing the strength is rather low, (method 1); Tissue cleaning is good, (method 2), but this only applies on the case with a good surface finish, (in this case it is a ground surface). Method 3 gives a good strength, which suitable for raw material surface or a surface with a poor surface finish; the result of method 4 is the average value of Table 3 for the film thickness of $1 \mathrm{~mm}$.

Because it is a one-off test with regard to the test variation, the results of the methods 2,3 and 4 are on the similar level.

\subsection{Strength and safety}

Adhesive grippers are much smaller than the work piece size in most of the cases, hence the joint (adhesive film) can be considered as points and adhesive grippers are not good to bear the load of torque and moment. The gripper diameter is relatively small, so if a little torque or moment is applied on the top of the gripper, a higher stress can be produced on the edge of the adhesive film and the joint can be broken. So the adhesive joint by a gripper can be supposed to stand for forces only in 3D space rather than moment.

The strength criteria and safety coefficient are proposed and the strength criteria are validated by the tests of the gripper with angled top.

\subsubsection{Strength criteria}

Adhesive gripper is axisymmetric about its central line as well as the adhesive film on the top, as shown in Fig. 13. Tensile strength, $\sigma_{\mathrm{t} 0}$, and compression strength, $\sigma_{\mathrm{c} 0}$, are in the $z$ 
Fig. 5 Gripper shear load capacity test, $F_{\mathrm{s} 0}, N$, curing time $60 \mathrm{~s}$ and $A=1.07 \times 10^{-4} \mathrm{~m}^{2}$

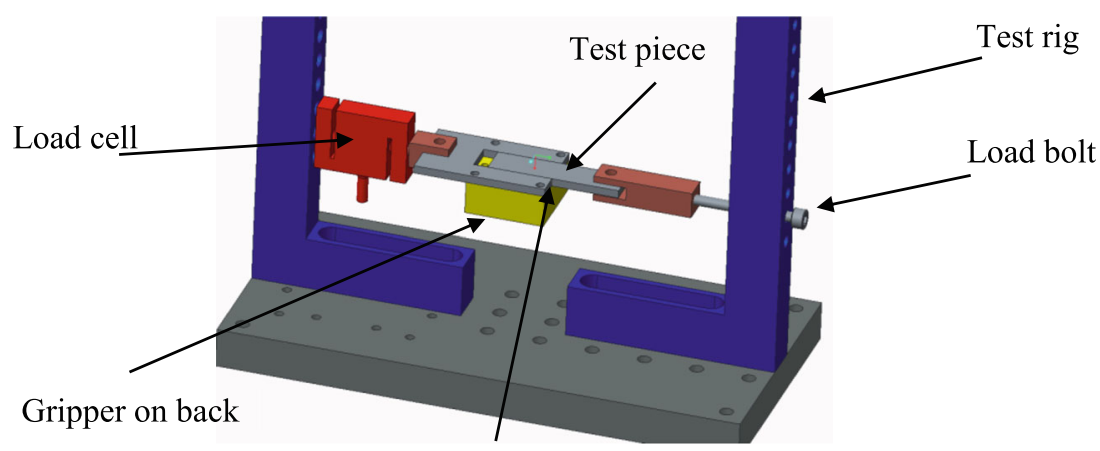

Joint surface direction; and shear strength, $\sigma_{\mathrm{s} 0}$, are in $x$ and $y$ axes. On the strength sphere, 6 vertices are available, which are $\left(\sigma_{\mathrm{s} 0}, 0,0\right)$, $\left(0, \sigma_{\mathrm{s} 0}, 0\right),\left(0,0, \sigma_{\mathrm{t} 0}\right),\left(0,-\sigma_{\mathrm{s} 0}, 0\right),\left(-\sigma_{\mathrm{s} 0}, 0,0\right)$ and $\left(0,0,-\sigma_{\mathrm{c} 0}\right)$.

With the given vertices, the strength sphere of the adhesive joint on the top of the gripper is

$$
\left\{\begin{array}{l}
\left(\frac{\sigma_{\mathrm{x}}}{\sigma_{\mathrm{s} 0}}\right)^{2}+\left(\frac{\sigma_{\mathrm{y}}}{\sigma_{\mathrm{s} 0}}\right)^{2}+\left(\frac{\sigma_{\mathrm{z}}}{\sigma_{\mathrm{t} 0}}\right)^{2}=1,\left(\sigma_{\mathrm{z}}>0\right) \\
\left(\frac{\sigma_{\mathrm{x}}}{\sigma_{\mathrm{s} 0}}\right)^{2}+\left(\frac{\sigma_{\mathrm{y}}}{\sigma_{\mathrm{s} 0}}\right)^{2}+\left(\frac{\sigma_{\mathrm{z}}}{-\sigma_{\mathrm{c} 0}}\right)^{2}=1,\left(\sigma_{\mathrm{z}} \leq 0\right)
\end{array}\right.
$$

When $\sigma_{\mathrm{z}}$ is negative, the tensile strength does not apply and the compression strength is the true strength limit. However, for the thin film of adhesive, the compression strength is so hard to test, which is out of the test rig capability. Generally, the compression strength will be much higher than the tensile strength and in a machining application the machining force will not be able to challenge the compression strength of the joint if the gripper is applied in the right arrangement.

\subsubsection{Safety coefficient}

In order to design a good fixture, we need to establish if the holding strength is adequate. The safety coefficient, $S$, is a value to evaluate the strength in stock in adhesive gripper application which is defined as

$$
\left\{\begin{array}{l}
S=\frac{1}{\sqrt{\left(\frac{\sigma_{\mathrm{x}}}{\sigma_{\mathrm{s} 0}}\right)^{2}+\left(\frac{\sigma_{\mathrm{y}}}{\sigma_{\mathrm{s} 0}}\right)^{2}+\left(\frac{\sigma_{\mathrm{z}}}{\sigma_{\mathrm{t} 0}}\right)^{2}}},\left(\sigma_{\mathrm{z}}>0\right) \\
S=\frac{1}{\sqrt{\left(\frac{\sigma_{\mathrm{x}}}{\sigma_{\mathrm{s} 0}}\right)^{2}+\left(\frac{\sigma_{\mathrm{y}}}{\sigma_{\mathrm{s} 0}}\right)^{2}+\left(\frac{\sigma_{\mathrm{z}}}{-\sigma_{\mathrm{c} 0}}\right)^{2}}},\left(\sigma_{\mathrm{z}} \leq 0\right)
\end{array}\right.
$$

When $\sigma_{\mathrm{c} 0}=\infty$, Eq. (4) can be simplified as

$$
\left\{\begin{array}{l}
S=\frac{1}{\sqrt{\left(\frac{\sigma_{\mathrm{x}}}{\sigma_{\mathrm{s} 0}}\right)^{2}+\left(\frac{\sigma_{\mathrm{y}}}{\sigma_{\mathrm{s} 0}}\right)^{2}+\left(\frac{\sigma_{\mathrm{z}}}{\sigma_{\mathrm{t} 0}}\right)^{2}}},\left(\sigma_{\mathrm{z}}>0\right) \\
S=\frac{1}{\sqrt{\left(\frac{\sigma_{\mathrm{x}}}{\sigma_{\mathrm{s} 0}}\right)^{2}+\left(\frac{\sigma_{\mathrm{y}}}{\sigma_{\mathrm{s} 0}}\right)^{2}},\left(\sigma_{\mathrm{z}} \leq 0\right)}
\end{array}\right.
$$

Alternatively, using the value of the tensile strength as that of the compression strength makes the design much safer in compression, and Eq. (4) can be written as

$S=\frac{1}{\sqrt{\left(\frac{\sigma_{\mathrm{x}}}{\sigma_{\mathrm{s} 0}}\right)^{2}+\left(\frac{\sigma_{\mathrm{y}}}{\sigma_{\mathrm{s} 0}}\right)^{2}+\left(\frac{\sigma_{\mathrm{z}}}{\sigma_{\mathrm{t} 0}}\right)^{2}}}$

In the adhesive gripper application, the safety coefficient of any grippers must be higher than a given minimum allowable safety coefficient, $S_{0}$, which is recommended as 1.5 in common application and 2.0 in some important or critical applications.
Fig. 6 Shear load on the gripper top
Test piece

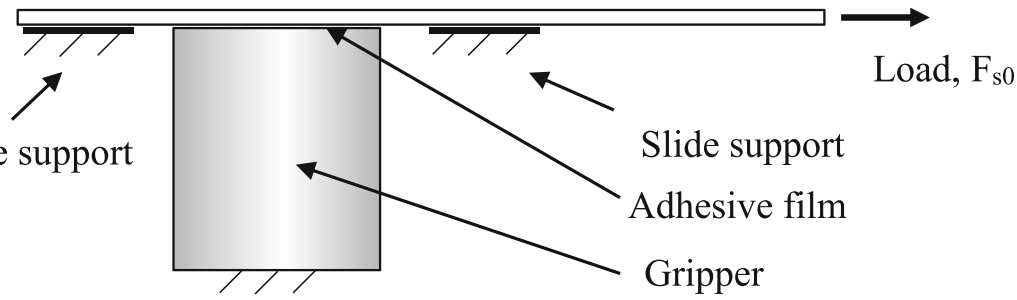




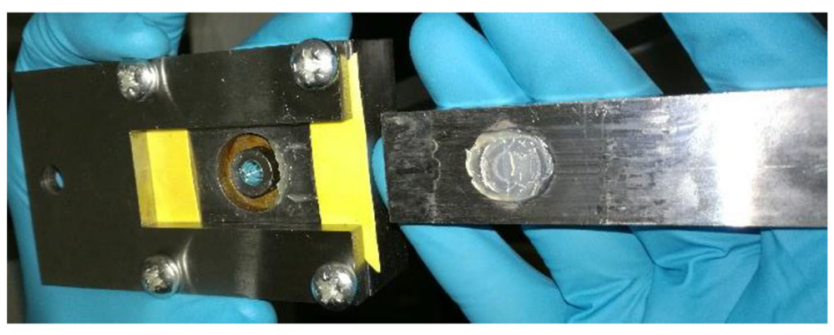

Fig. 7 Breakage happens on the gripper top in the shear test

$S \geq S_{0}$

If the yield strengths, of tensile and shear, are used as the strength limits, the allowable safety coefficient, $S_{0}$, can be lower than the recommended values, such as 1.25 and 1.5.

\subsubsection{Strength criteria verification}

The grippers with angled tops of (a) $90^{\circ}$ (butting), (b) $67.5^{\circ}$ and (c) $45^{\circ}$ can be used to verify the proposed strength criteria, as shown in Fig. 14. The constant diameter of the gripper used is $d=10 \mathrm{~mm}$.

The load capacity of the angled gripper is listed in Table 5 [17]. It is observed that the gripper with angled top got a reduced load capacity at first (at $67.5^{\circ}$ ) and when the angle is further reduced to $45^{\circ}$, the load capacity increased rather than decreasing.

When the angle is $90^{\circ}$, the joint strength equals the tensile strength of the adhesive film, $\sigma_{\mathrm{t} 0}=28.62 \mathrm{MPa}$. According to the strength criteria, the strength of the adhesive film is

$\left(\frac{\sigma_{\mathrm{s}}}{\sigma_{\mathrm{s} 0}}\right)^{2}+\left(\frac{\sigma_{\mathrm{t}}}{\sigma_{\mathrm{t} 0}}\right)^{2}=1$

Submit the strength with angle of $45^{\circ}$ or $67.5^{\circ}$ and the tensile strength, $\sigma_{\mathrm{t} 0}$, into Eq. (8) and the shear strength of the adhesive film is obtained, as $\sigma_{\mathrm{s} 0}=11.40 \mathrm{MPa}$ and $6.89 \mathrm{MPa}$ respectively and the average shear strength is $9.15 \mathrm{MPa}$.

When the top angle is $90^{\circ}$ (butting), the load capacity of the gripper is descripted as Eq. (1).

Table 3 Adhesive shear load capacity, $F_{\mathrm{s} 0}(N)$, curing time $60 \mathrm{~s}$ and $A=$ $1.07 \times 10^{-4} \mathrm{~m}^{2}$

\begin{tabular}{lllllll}
\hline \multicolumn{7}{c}{ Thickness, mm } \\
\cline { 2 - 7 } Test & 0.5 & 1.0 & 1.5 & 2.0 & 2.5 & 3.0 \\
\hline 1 & 1540 & 1310 & 1230 & 1220 & 1180 & 1290 \\
2 & 1590 & 1260 & 1230 & 1250 & 1160 & 1040 \\
3 & 1350 & 1100 & 1200 & 1330 & 1330 & 999 \\
4 & 1220 & 1290 & 1190 & 1280 & 1240 & 1220 \\
5 & 1240 & 1310 & 1240 & 1310 & 1370 & 1020 \\
Average & 1388 & 1254 & 1218 & 1278 & 1256 & 1114 \\
\hline
\end{tabular}

Table 4 Adhesive shear strength, $\sigma_{\mathrm{s} 0}(\mathrm{MPa})$, with curing time of $60 \mathrm{~s}$

\begin{tabular}{lllllll}
\hline \multirow{7}{*}{ Test } & \multicolumn{2}{l}{ Thickness, $\mathrm{mm}$} \\
\cline { 2 - 7 } & 0.5 & 1.0 & 1.5 & 2.0 & 2.5 & 3.0 \\
\hline 1 & 14.12 & 12.01 & 11.28 & 11.19 & 10.82 & 11.83 \\
2 & 14.58 & 11.55 & 11.28 & 11.46 & 10.64 & 9.53 \\
3 & 12.38 & 10.09 & 11.00 & 12.19 & 12.19 & 9.16 \\
4 & 11.19 & 11.83 & 10.91 & 11.74 & 11.37 & 11.19 \\
5 & 11.37 & 12.01 & 11.37 & 12.01 & 12.56 & 9.35 \\
average & 12.73 & 11.50 & 11.17 & 11.72 & 11.52 & 10.21 \\
Variation, $\pm \%$ & 14.5 & 4.4 & 1.8 & 4.0 & 9.0 & 16.5 \\
\hline
\end{tabular}

The variation is the maximum deviation from the average divided by the average

When the top angle is $\alpha$, the top surface area, $A$, is

$A=\frac{A_{0}}{\sin \alpha}$

where $A_{0}$ is the gripper section area, $A_{0}=\pi d^{2} / 4$.

The tensile stress, $\sigma_{\mathrm{t}}$, is

$\sigma_{t}=\frac{F \sin (\alpha)}{A}$

and the shear stress, $\sigma_{\mathrm{s}}$, is

$\sigma_{s}=\frac{F \cos (\alpha)}{A}$

The definition of the shear-tensile strength ratio is

$\lambda=\frac{\sigma_{\mathrm{s} 0}}{\sigma_{\mathrm{t} 0}}$

which is related to adhesive specification and equals 0.3197 for the specific adhesive used in [17].

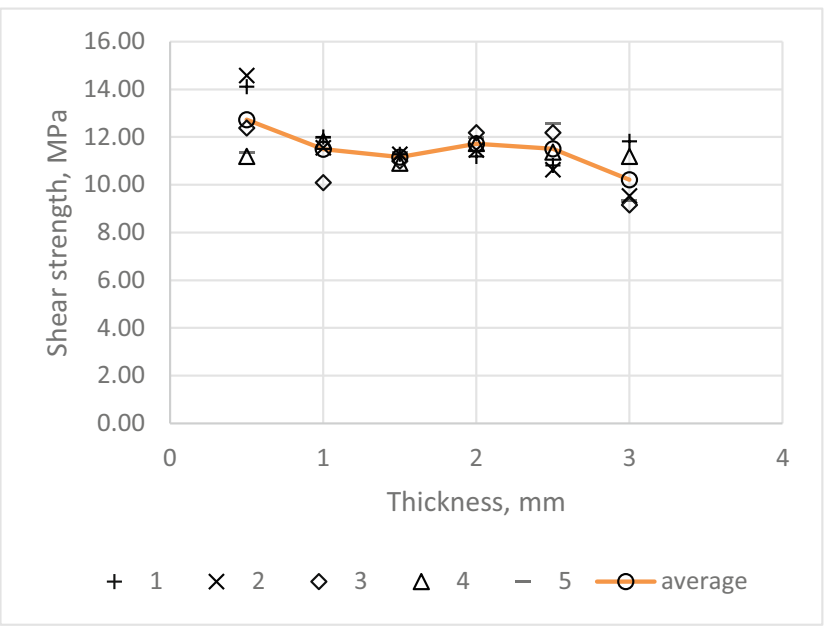

Fig. 8 Adhesive shear strength 


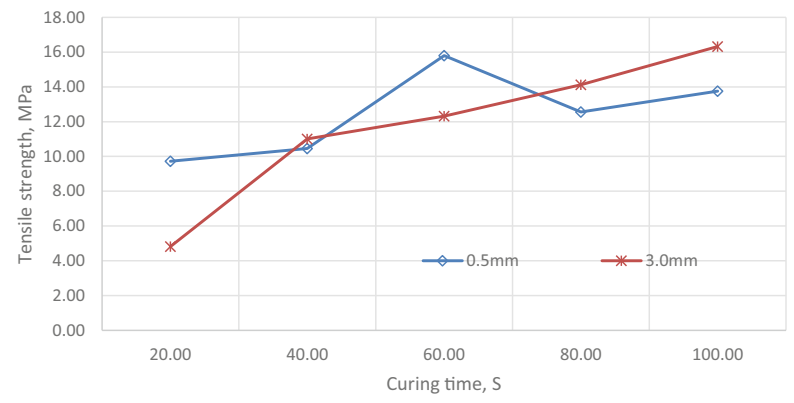

Fig. 9 Curing time and film thickness effects on film tensile strength

Submit Eqs. (9), (10), (11) and (12) into Eq. (3) and yield, $F=A_{0} \sigma_{\mathrm{t} 0} \Phi(\alpha, \lambda)$

where $\Phi$ is the angle effect function, which is

$$
\Phi(\alpha, \lambda)=\frac{2}{\sin (2 \alpha) \sqrt{\frac{1}{\lambda^{2}}+\tan ^{2}(\alpha)}},
$$

and when the top angle, $\alpha$, is $90^{\circ}, \Phi=1$ and when the top angle is $0^{\circ}, \Phi=\infty$.

The gripper top angle effect on the gripper load capacity is plotted in Fig. 15 from $90^{\circ}$ to $30^{\circ}$ as well as the experiment results [17] in triangle markers. The load capacity decreases gently in the beginning, then a little bit quicker and gently again until around 50 . The load capacity stops decreasing and then starts to increase. This trend explains the discovery of top angle effects very well, which is caused by the shear-tensile strength ratio. The error between the model and literature experiment [17] is caused by experimental errors and limited sample number. The film thickness also introduced an error on the top angle that made the angle of the break plane a little bigger than the top angle.

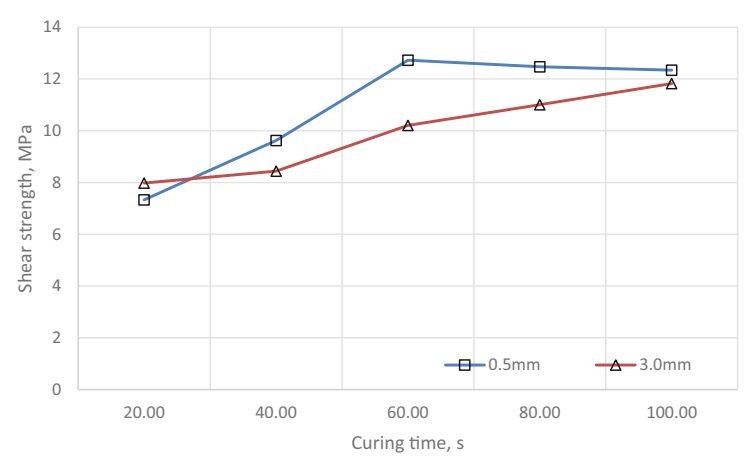

Fig. 10 Curing time and film thickness effects on film shear strength

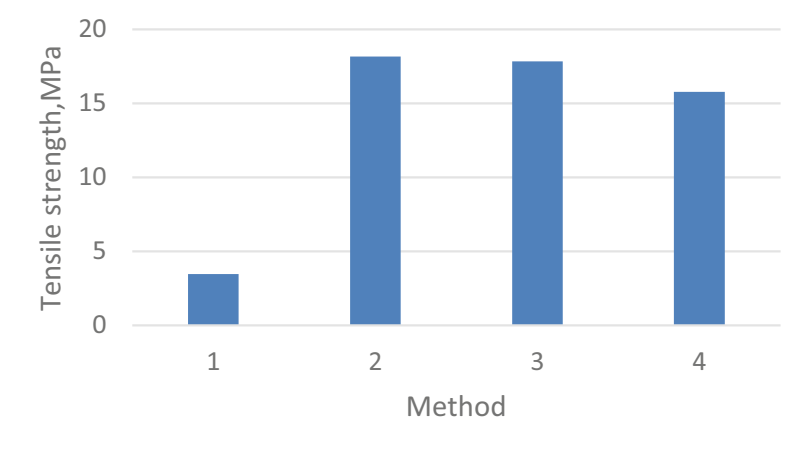

Fig. 11 Cleaning method effect on tensile strength

\section{Fixture and load calculation}

A dyno and fixture setup was prepared to test a square plate machined on the top, as shown in Fig. 16. The test piece is $200 \mathrm{~mm}$ in length and width, and $20 \mathrm{~mm}$ in thickness. Machining is done on the top surface and machining process is surface grinding. Two safety holes are designed in the middle and two bolts M12 goes through with a gap of $2 \mathrm{~mm}$ in radius to avoid dropping down and damage to the machine tool. The material of the test piece is EN8.

Actually, the design method is suitable for any geometries and machining methods, not limited to the presented geometry and machining method.

The fixture demo is as shown in Fig. 16, three grippers are arranged on the base plate to keep the maximum distance between each other and maximize the work holding capability. The base plate is bolted on to the connection plate with 4 posts as spacers with the same height and the dyno is fixed on back of the connection plate.

The dynamometer used is KISTLER 9272 for measurement of cutting forces on the part. The measuring range is \pm $5 \mathrm{kN}$ for Fx and Fy, and the linearity is less than $\pm 1 \%$ full scale. Channels of $\mathrm{Fz}$ and $\mathrm{Mz}$ are available but they are not mandatory.

The adhesive film thickness is $1.0 \mathrm{~mm}$ adjusted by a shim set, which is removed after curing. The curing time used is the recommended value, $60 \mathrm{~s}$.

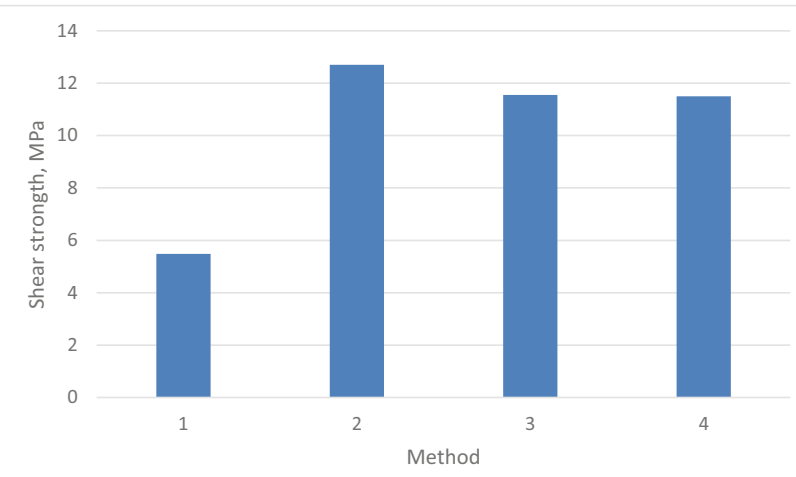

Fig. 12 Cleaning method effect on shear strength 


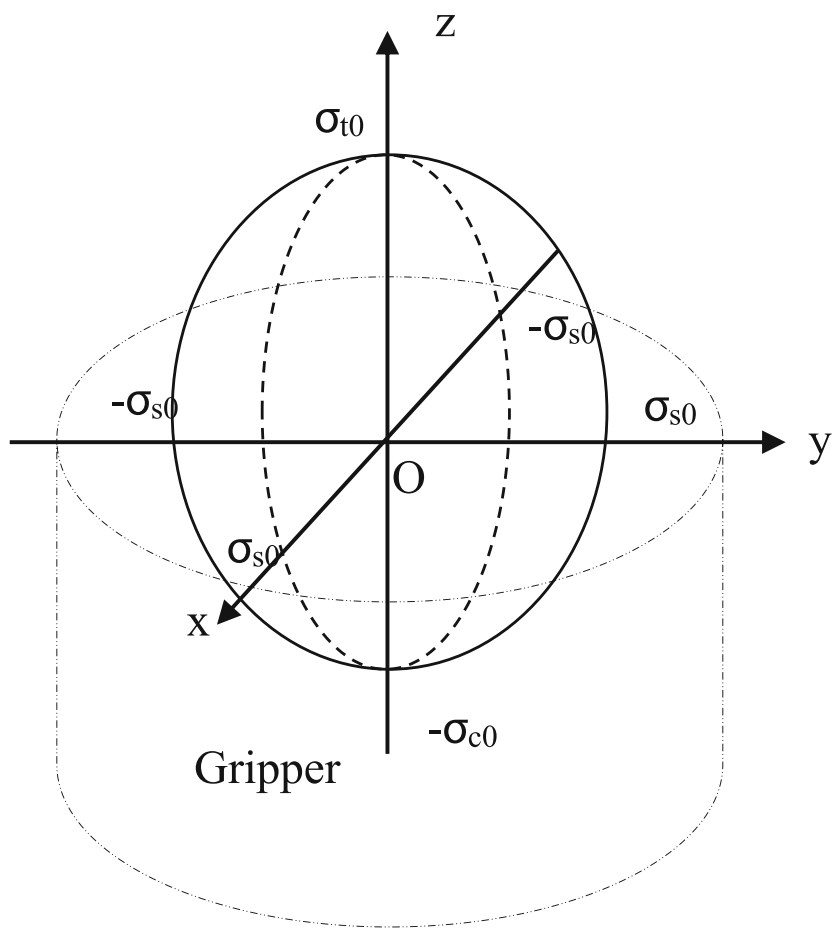

Fig. 13 Adhesive joint 3D strength sphere

The three grippers, a, b and c, as shown in Fig. 16, share machining load but not equally. The load share depends on test piece geometry, gripper arrangement, base plate Young's modulus and Poison ratio etc. Finite element analysis can help to acquire the shared machining load on each gripper with unit load, (100 N used for FEA), in $x$ and $y$.

Three areas, a, b and c, of $11.67 \mathrm{~mm}$ in diameter are applied fixed constrains and a force, $\mathrm{Fx}^{\prime}$ and $\mathrm{Fy}^{\prime}$, of $100 \mathrm{~N}$ in $x$ and $y$, to the surface separately applied on the top at points 1,2 and 3 individually. Six simulations carried out to help us understand how the gripper share machining load, as shown in Fig. 17. The simulation results are listed in Table 6 .

In the machining, $\mathrm{Fy}^{\prime}, \mathrm{Fx}^{\prime}$ and $\mathrm{Fz}^{\prime}\left(\mathrm{Fz}^{\prime}=0\right.$ in the demo) are applied simultaneously and they produce components force on every gripper in $x, y, z$. Based on linear superposition, the

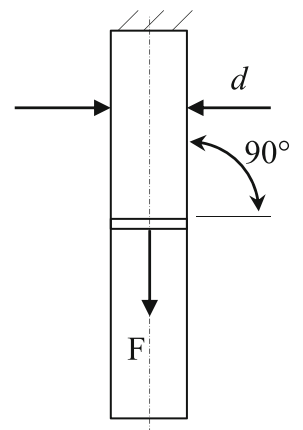

(a)

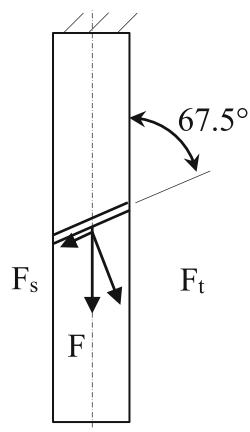

(b)

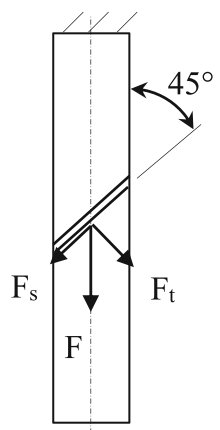

(c)
Fig. 14 Grippers with angled top
Table 5 Load capacity of angled grippers and stresses, $d=10 \mathrm{~mm}$

\begin{tabular}{|c|c|c|c|}
\hline & 90 & $\begin{array}{l}\text { Gripper top angle, } \\
67.5\end{array}$ & 45 \\
\hline Load, kN & 2.25 & 1.35 & 1.66 \\
\hline$\sigma, \mathrm{MPa}$ & 28.62 & 15.58 & 14.97 \\
\hline$\sigma_{\mathrm{t}}, \mathrm{MPa}$ & 28.62 & 14.39 & 10.59 \\
\hline$\sigma_{\mathrm{s}}, \mathrm{MPa}$ & 0 & 5.96 & 10.59 \\
\hline
\end{tabular}

components in the same direction on the same gripper can be summed up as a combined result.

The machining force on point $j$ in direction $m$ which produces a gripper load on gripper $i$ in direction $k$ is defined as $F_{\mathrm{i}, \mathrm{k}, \mathrm{j}, \mathrm{m}}$, according to principle of linear superposition, and the work holding force on the gripper $i$ in direction $k$ produced by machining force on point $j$ is

$F_{\mathrm{i}, \mathrm{k}, \mathrm{j}}=\sum_{m=\mathrm{x}, \mathrm{y}, \mathrm{z}} \eta_{\mathrm{i}, \mathrm{k}, \mathrm{j}, \mathrm{m}} F_{\mathrm{m}}{ }^{\prime}$

where $i=a, b, \mathrm{c}, k=x, y, z, j=1,2,3$ and $\eta_{\mathrm{i}, \mathrm{k}, \mathrm{j}, \mathrm{m}}$ is the nondimensional force transmission coefficient, which is the force in Table 6 divided by $100 \mathrm{~N}$.

The stress of gripper $i$ produced by machining force on point $j$ is

$\sigma_{\mathrm{i}, \mathrm{k}, \mathrm{j}}=\frac{F_{\mathrm{i}, \mathrm{k}, \mathrm{j}}}{A_{\mathrm{i}}}$,

where $A_{\mathrm{i}}$ is the area of the gripper $i$.

The safety coefficient of the gripper $i$ when machining on point $j$ can be calculated by submitting the gripper stress, $\sigma_{\mathrm{i}, \mathrm{k}, \mathrm{j}}$, into Eq. (4),

$S_{\mathrm{i}, \mathrm{j}}=\frac{1}{\sqrt{\left(\frac{\sigma_{\mathrm{i}, \mathrm{x}, \mathrm{j}}}{\sigma_{\mathrm{s} 0}}\right)^{2}+\left(\frac{\sigma_{\mathrm{i}, \mathrm{y}, j}}{\sigma_{\mathrm{s} 0}}\right)^{2}+\left(\frac{\sigma_{\mathrm{i}, \mathrm{z}, \mathrm{j}}}{\sigma_{\mathrm{t} 0}}\right)^{2}}}$.

Due to the cutting force components, $\mathrm{Fx}^{\prime}, \mathrm{Fy}^{\prime}$ and $\mathrm{Fz}$ ', depending on machining method, such as grinding,

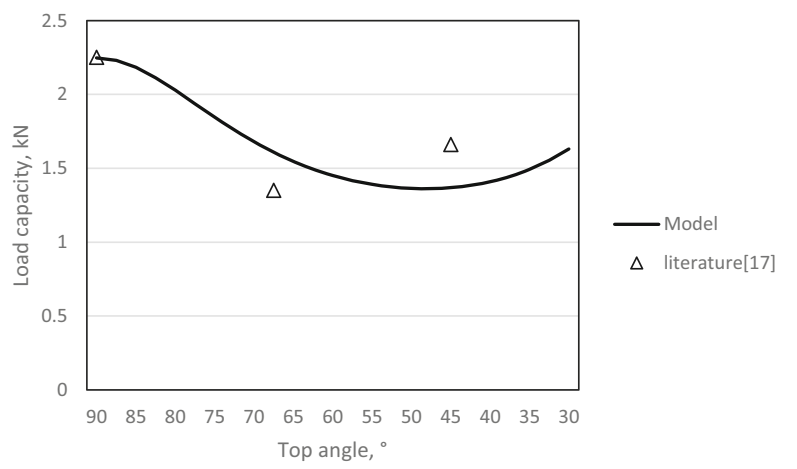

Fig. 15 Gripper top angle effect on the load capacity 
Fig. 16 Test piece and fixture design with 3 grippers and dyno

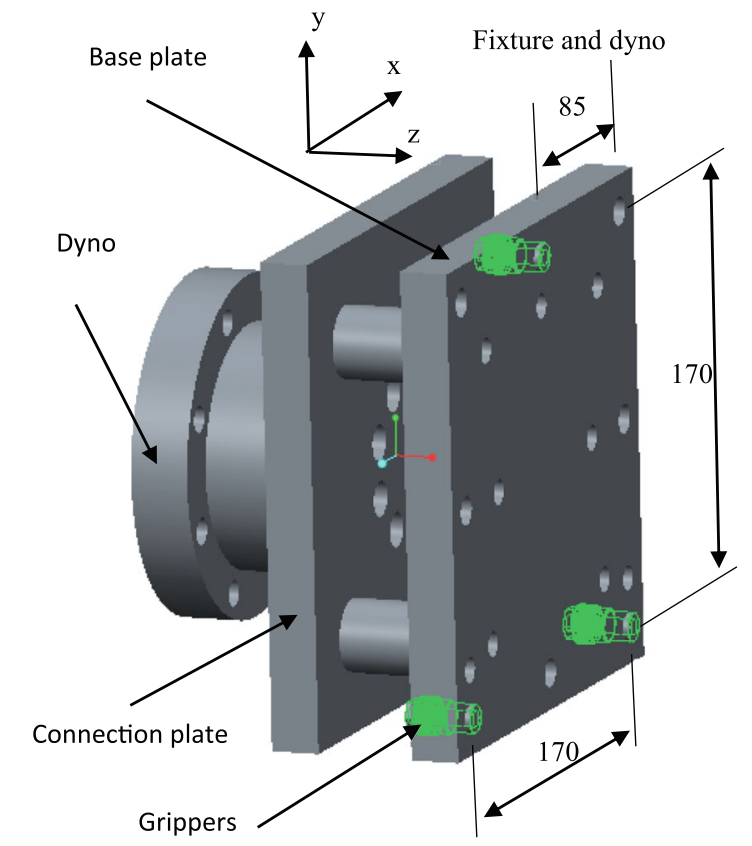

Test piece

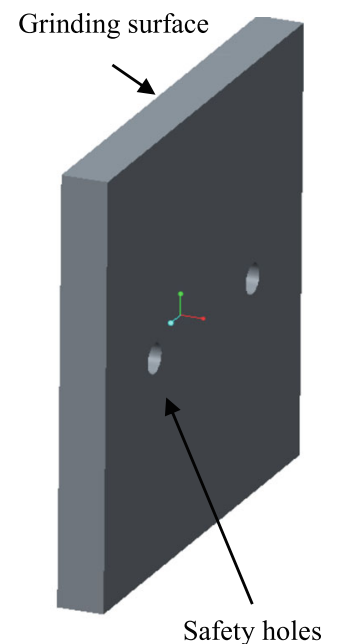

- Surface speed: $35 \mathrm{~m} / \mathrm{s}$

- Feed speed: $1000 \mathrm{~mm} / \mathrm{min}$

- Coolant: 70 bar and 120 1/min

- Grinding width: $20 \mathrm{~mm}$

The fixture setup is as shown in Fig. 19. Four grinding tests with grinding depth of $0.1,0.5,0.75$ and $1.0 \mathrm{~mm}$ have been carried out and the maximum grinding forces are listed in Table 7 . The safety coefficients of the critical point, which is the minimum value within points, a, b and c, are also listed. In every cut, the critical point keeps the same point a, and the minimum safety coefficient is 8.3 .

Grinding machine used in the test is Makino G7. Machining parameters are the followings:

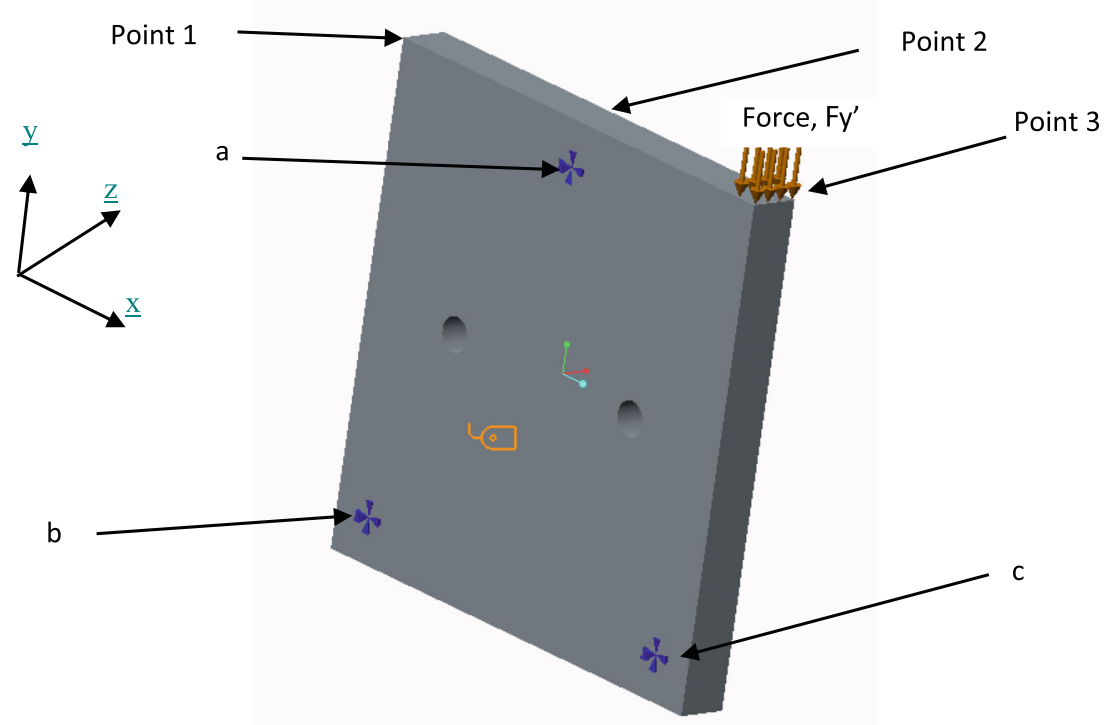


Table $6100 \mathrm{~N}$ cutting force $\mathrm{Fy}^{\prime}$ and $\mathrm{Fx}^{\prime}$, produced loads on grippers, $N$

\begin{tabular}{|c|c|c|c|c|c|c|c|c|c|c|}
\hline \multirow{2}{*}{$\frac{\text { Gripper }}{\text { Load in }}$} & & \multicolumn{3}{|l|}{$\mathrm{a}$} & \multicolumn{3}{|l|}{$\mathrm{b}$} & \multicolumn{3}{|l|}{$\mathrm{c}$} \\
\hline & & $X$ & $Y$ & $Z$ & $X$ & $Y$ & $Z$ & $X$ & $Y$ & $Z$ \\
\hline \multirow[t]{2}{*}{ Point 1} & $\mathrm{Fx}$ & 38.4 & -34.8 & -4.8 & 9.5 & 9.5 & 2.38 & 52 & 13.4 & 2.46 \\
\hline & Fy, & 4.2 & 81.0 & -0.04 & 25.0 & 10.0 & 4.7 & -29.5 & 8.3 & -4.6 \\
\hline \multirow[t]{2}{*}{ Point 2} & Fx, & 60.7 & 0 & -5.0 & 19.6 & 4.4 & 2.5 & 19.6 & -4.4 & 2.5 \\
\hline & Fy, & 0 & 83.0 & 0 & 25 & 8.5 & 4.66 & -25 & 8.5 & -4.6 \\
\hline \multirow[t]{2}{*}{ Point 3} & $\mathrm{Fx}$, & 38.4 & 35.0 & -4.8 & 52 & -13.4 & 2.5 & 9.5 & -21.4 & 2.4 \\
\hline & Fy, & -4.0 & 81 & 0.037 & 29.5 & 8.3 & 4.66 & -25 & 10 & -4.6 \\
\hline
\end{tabular}

In the test with grinding depth of $1.0 \mathrm{~mm}$, the spindle power reached the power limit and the grinding depth cannot be further increased because of the surface burning, the safety coefficient is 8.34 in the cut and the grinding process cannot challenge the work holding strength in this case clearly.

\section{Conclusion and recommendations}

On the base of the test and analysis, the following conclusions can be drawn:

1. The UV adhesive gripper can achieve a maximum tensile load capacity of $1388 \mathrm{~N} / 12.97 \mathrm{MPa}$ and minimum load capacity of $1113.8 \mathrm{~N} / 10.41 \mathrm{MPa}$ and a maximum shear

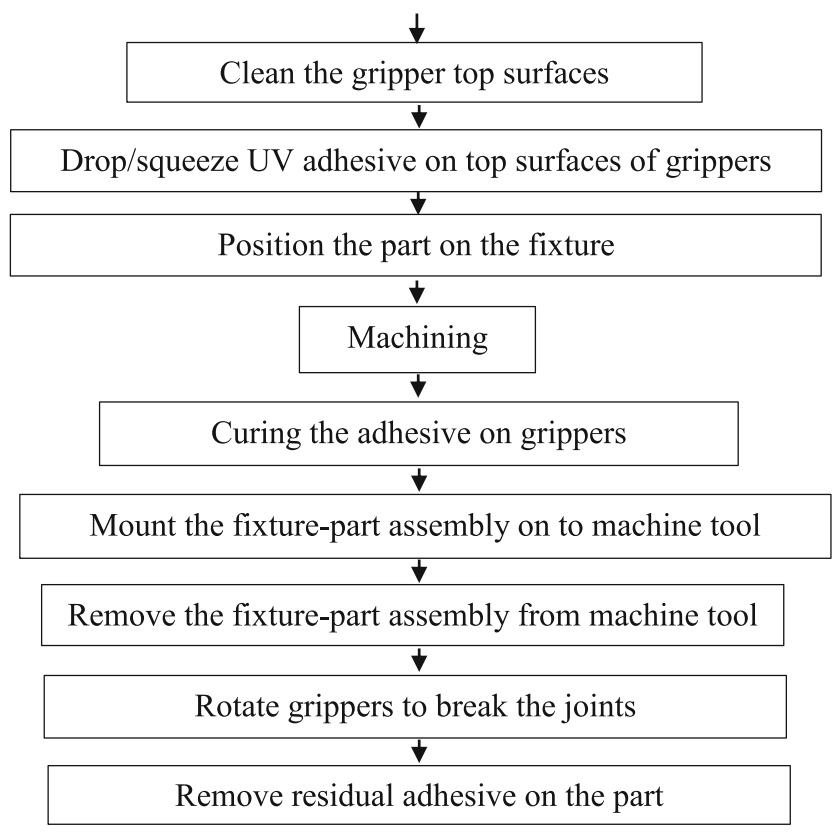

Fig. 18 Adhesive fixture operation flow chart load capacity of $127.3 \mathrm{~N} / 1.19 \mathrm{MPa}$ and minimum shear load capacity of $102.1 \mathrm{~N} / 0.95 \mathrm{MPa}$, with the given adhesive specification, BlueGrip S2, curing time of $60 \mathrm{~s}$ and top surface diameter of $11.68 \mathrm{~mm}$. The strength variation is $\pm 19.9 \%$ for tensile strength and $\pm 16.5 \%$ for shear strength.

2. A thicker adhesive film requires a longer curing time. The recommended curing time, $60 \mathrm{~s}$, is suitable for the recommended film thickness of $1.0 \mathrm{~mm}$. If the film thickness is more than $1.0 \mathrm{~mm}$, the curing time should increase accordingly.

3. Most of the time, the adhesive gripper is rather small compared with the part size and it is not good at moment and torque application. In practice, a good gripper arrangement is required to avoid moment and torque load applied on the adhesive joint.

4. In application, tensile load and shear load will happen at the same time and the strength criteria can be used as combined strength limit, which is an ellipsoid with 6

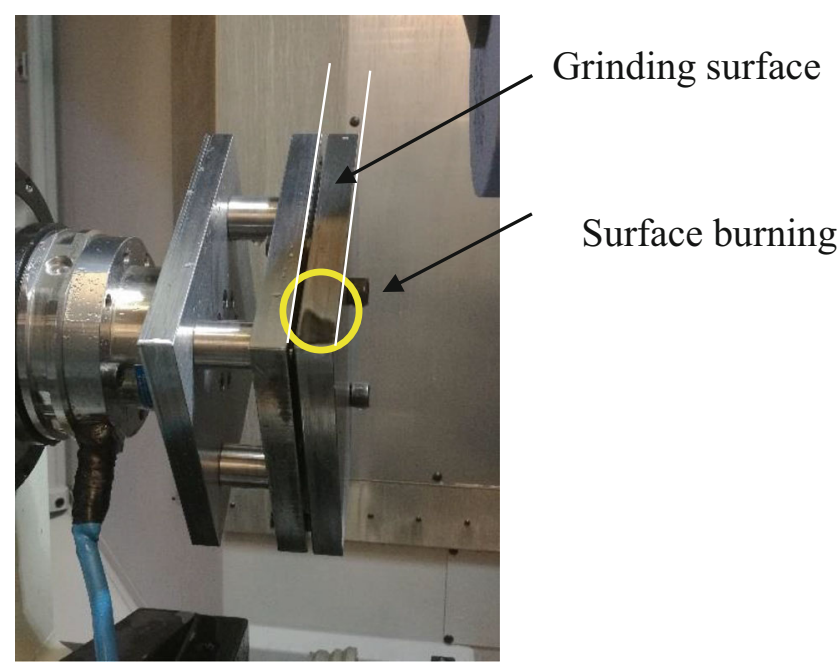

Fig. 19 Grinding test setup, with grinding depth of $0.75 \mathrm{~mm}$, surface burning happened at the end of the surface 
Table 7 Grinding force and safety coefficient, grinding width $20 \mathrm{~mm}$

\begin{tabular}{lllll}
\hline Test & 1 & 2 & 3 & 4 \\
\hline Grinding depth, mm & 0.1 & 0.5 & 0.75 & 1.0 \\
Fx, $N$ & 30 & 300 & 450 & 690 \\
Fy, $N$ & 45 & 50 & 80 & 65 \\
$S$ & 980 & 48.2 & 21.7 & 8.3 \\
Critical point & $\mathrm{a}$ & $\mathrm{a}$ & $\mathrm{a}$ & $\mathrm{a}$ \\
\hline
\end{tabular}

vertexes, $\left(\sigma_{\mathrm{s} 0}, 0,0\right),\left(0, \sigma_{\mathrm{s} 0}, 0\right),\left(0,0, \sigma_{\mathrm{t} 0}\right),\left(0,-\sigma_{\mathrm{s} 0}, 0\right)$, $\left(-\sigma_{\mathrm{s} 0}, 0,0\right)$ and $\left(0,0,-\sigma_{\mathrm{c} 0}\right)$, where $\sigma_{\mathrm{s} 0}$ is the shear strength, $\sigma_{\mathrm{t} 0}$ is the tensile strength and $\sigma_{\mathrm{c} 0}$ is the compression strength; if the compression strength is not available, the tensile strength can be used to take place of it, which will make the fixture design safer.

5. For specific applications, finite element analysis can be used to acquire gripper component share coefficients of the machining force for a specific part geometry and gripper arrangement.

6. Gripper safety coefficients can be calculated on the base of both FEA simulation and cutting force calculation to evaluate the joint strength is enough or not; the minimum allowable safety coefficient recommended is 1.5 and 2.0 for some critical application to cover strength variation and the other unexpected effects; if the yield strength is used, the allowable safety coefficient can be reduced, such as to 1.25 and 1.5 .

7. With a good gripper arrangement, the UV adhesive work holding is strong enough for grinding and reasonably the same result can be expected for milling and turning.

8. Degreasing is mandatory for surface preparation. Recommended cleaning method for surface preparation is good enough for a high-quality machining surface. In some application, if the surface finish is not good, such as raw material, pressure air blow is one option to take place of tissue.

The assessment method is not limited to UV adhesive and the given gripper specification. The other adhesive and/or specification, such as thermal adhesive, can be tested with the same method. After the tensile and shear strengths and their variations have been tested, the FEA-based fixture design method can be used for most of work holding cases with various part geometries and the precondition is that the safety coefficient should be big enough to cover the variation and yield failure.

Acknowledgements The authors would like to acknowledge the in kind contribution of NCMT on the experiments.

Funding information The research is financially supported by Catapult, project code: 152590 .
Open Access This article is distributed under the terms of the Creative Commons Attribution 4.0 International License (http:// creativecommons.org/licenses/by/4.0/), which permits unrestricted use, distribution, and reproduction in any medium, provided you give appropriate credit to the original author(s) and the source, provide a link to the Creative Commons license, and indicate if changes were made.

\section{References}

1. Morgan G (1999) Workholding with fusible alloys. Aircr Eng Aerosp Technol 71(6):576-578

2. Rong Y, Tao R, Tang X (2000) Flexible fixturing with phase change materials: part 1 experimental study on magnetorheological fluids. Adv Manuf Technol 16:822-829

3. Ivan G. Sears, Robin Steveson, Roland J. Menassa (2007) Magnetorheological reconfigurable clamp for a flexible manufacturing system. US7204481B2

4. Sarma SE, Paul K (1997) Wright reference free part encapsulation: a new universal fixturing concept. J Manuf Syst 16(1):35-47

5. Kang P, Yang H (2017) New bending system using a segmented vacuum chuck for stressed mirror polishing of thin mirrors. Curr Opt Photonics 1(6):618-625

6. Mantriota G, Messina A (2011) Theoretical and experimental study of the performance of flat suction cups in the presence of tangential loads. Mech Mach Theory 46:607-617

7. Raymond Leon, Jr (1999) Adjustable magnetic jig US5971379

8. Chihung Shen, Yhutin Lin (2006) Reconfigurable magnetic fixturing pallets for an assembly line. US7055679B2

9. Clifford Stead (1967) Magnetic chucks US3336551

10. Adhesives, Glues and Sealants (2018) Adhesive Introduction. https://www.adhesiveandglue.com, (accessed 10th Nov. 2018)

11. DE Meter, Eward, C (2016) Method and devices to minimize work piece distortion due to adhering stresses and changes in internal stresses WO2016014482

12. Chihung Shen, Yhutin Lin (2009) Adhesive based reconfigurable pallet system for assembly lines. US 7484464B2

13. Doll KR, De Meter EC (2016) Investigation of workpiece distortion during the photopolymerization of a PAAW joint. J Manuf Sci Eng 138:111008

14. De Meter EC (2005) Characterization of the quasi-static deformation of LAAG joints adhering machined steel surfaces. Trans ASME J Manuf Sci Eng 127:350-357

15. De Meter EC, Kumar JS (2010) Assessment of photo-activated adhesive workholding (PAW) technology for holding hard-to-hold workpieces for machining. J Manuf Syst 29:19-28

16. De Meter EC (2004) Light activated adhesive gripper (LAAG) workholding technology and process. J Manuf Process 6(2):201-214

17. Raffles MH, Kolluru K, Axinte D, Llewellyn-Powell H (2013) Assessment of adhesive fixture system under static and dynamic loading conditions. Proc IMechE B J Eng Manuf 227(2):267-280

18. Blue Photon Technology \& Workholding Systems LLC (2018) Work Holding System. https://www.bluephotongrip.com, (accessed 10th Nov. 2018)

19. Force Logic UK (2018) Load cell sensors. https://force-logic.co.uk, (accessed 10th Nov 2018)

20. Master Fluid Solutions (1998) MicroSol® Products. https:// masterfluidsolutions.com, (accessed 10th Nov 2018)

Publisher's note Springer Nature remains neutral with regard to jurisdictional claims in published maps and institutional affiliations. 